colic preceding the jaundice, and with gall-stone obstruction of the common duct we do not usually find an enlarged gall bladder. However, the swelling in this case was very hard, and not in the usual position of a distended gall bladder, nor did it move with respiration as freely as one would expect a sall bladder to do.

The patient was young for malignant disease of the head of the pancreas, pressing on the common duct, and the repeated attacks of jaundice were unlike obstruction of the duct from new growths, and were indeed suggestive rather of gall-stone obstruction. Gall-stone obstruction seemed the more likely cause, but it did not seem a straightforward case of this kind.

It is a very interesting question why the jaundice varied from time to time. It seems to me that the probable explanation must be that for days or weeks the amount of fluid in the cyst, and therefore the tension, varied, and as this varied so the pressure on the bile duct was diminished or increased. It was also very remarkable that before the patient was under the anaesthetic at the time of the second operation, neither cyst should have caused sufficient bulging to lead to its discovery, and that even with the abdominal wall relaxed under the anaesthetic the lower cyst could not be felt until the abdomen was opened. They both lay under the viscera and at considerable depth, and this was no doubt the explanation of the difficulty in their detection. It shows how retroperitoneal tumours of considerable size may escape detection, even when one is looking for them. The case also illustrates the difficulty which may be encountered in attempting to remove such cysts.

In the second case the fact that the cyst was not ovarian might have been suggested by the undue mobility upwards under the anaesthetic. I had not observed this before the anaesthetic was given, though I had noticed the possibility of lateral mobility. ${ }^{4}$ The inability to feel anything of the cumour on a vaginal exarnination was of no particular value as an indication that the tumour was not ovarian. The largest ovarian cyst I ever operated on I could feel nothing of either per vaginam or per rectum. I d do not know how the two large bosses present on the tumour are to be accounted for, for the cyst was unilocular; possibly it bulged more at these parts.

I have recorded ${ }^{5}$ another case of cyst of the mesentery, and in that case the tumour grew in the mesentery in a hernial sac and caused the irreducibility of the hernia. It was a small cyst with dense white wall of fibrous tissue, and on laying it open some soft partitions of what looked like fibrin were seen stretching across it. The fluid from it was slightly blood-stained and a little viscid, and on standing spontaneously coagulated into a jelly. Microscopic examination of the wall showed only fibrous tissue.

Other cases in which mesenteric cysts have been diagnosed as ovarian tumours are on record. ${ }^{6}$ An exhaustive accoun of mesenteric cysts, with references to many recorded cases, will be found in the papers of Moynihan and Dowd in the Annals of Surgery.

\section{NOTES AND REFERENCES.}

1 Quoted by Mayo Robson and Moynihan in Diseases of the Pancreas c903. 2 Loc. cit. 3 Loc. cit. 4 The lateral mobility has been considered a diagnostic feature of mesenteric cysts; also in some cases a band o resonance across the cyst has been observed. ${ }^{5}$ Lancet. 1896, ii, p. r678. Carter. BRITISH MEdiCAL JourNal, r883, i, p, 7 : and Knowsley Thornton, ibid., 1882, ii, p. 1242. 7 Vol. Xxi, p. r, and vol. Xxxii, p. 515.

\section{" RETROPERITONEAL MANIPULATION" :}

A METHOD OF SEPARATING DEEP-SEATED, PLASTIC, PERICAECAL OR OTHER PERITONEAL ADHESIONS.

By G. GORE-GILLON, M.D., F.R.C.S.E., Auckland, New Zealand.

Now and again the surgeon meets with cases of appendicitis in which the adhesions in the neighbourhood of the appendix are so extensive, solid, and deep seated that there seems to be no way out of the impasse. In the following case all the parts in the right iliac and pelvic region seemed to be massed together in one piece :

History.-G. E., male, aged 27 , single, took ill with appendicitis for the first time in February, roO2, in a distant part of New Zealand. He had another attack in August and again in October of the same year. That month he was operated on by a medical man who had three others with him. The operator; after long and tedious work in tying omental adhesions, was unable to find any trace of appendix, and so the abdome was closed up again. He suspected that the appendix was curled up behind the eaecum somewhere, but was unable to get at the caecum owing to dense adhesions in the right pelvic and iliac regions. The patient subsequently went to Melbourne and Sydney, and was in a private hospital in Melbourne, January, r903, with an acute attack. On returning to New Zealand in February, 1903 , he had another attack, and again in March and April. He had been taking hypodermic injections of morphine for the last seven months to relieve the almost constant pain.

State on Examination. - When he arrived in Auckland on April $23 \mathrm{rd}$ 1903, he looked very ill, and his weight was only $7 \mathrm{st}$. $8 \mathrm{lb}$. He had some trouble in emptying his bladder, and there was deep-seated tenderness in the right iliac region with some ill-defined thickening there. His temperature was normal. The blood count was normal.

Operation.-On April 26th I opened his abdomen, four other surgeons being present, and, having decided to get at the hidden appendix by the back way, I made an incision $3 \mathrm{~cm}$. internal to the anterior superior spine of the ileum (and to the outside of the former incision), and ex tended it for $9 \mathrm{~cm}$. above that point and $6 \mathrm{~cm}$. below it (somewhat similar to Crampton's incision for ligaturing the common iliac artery). The condition found was just what $I$ expected from the account given by the former operator-no sign of appendix, but just a close mass of adhesions, like a blank wall, lining the whole of that part of the abdominal cavity. The ileum disappeared into this mass low down and below it again; the end of the eaecum was attached by broad sessile adhesions to the right side of the bladder, which was pulled up somewhat. After a long and patient endeavour to separate the parts from the front I put into practice my plan of " retroperitoneal manipulation," and had it not'been for this method of attack I should have had to abandon the attempt as the former operators had done. I first divided the posterior peritoneum over the iliac fascia for about $6 \mathrm{~cm}$. just below the anterior superior spine, in the line of the skin incision, and then inserted my right little finger downwards (while the peritoneum with the intestines was held well forwards) till i felt it cross the external iliac artery, and then with my left little finger in the abdominal cavity in front, and as low down as the other finger, I worked one agains another, and soon felt a lump which was the appendix. By gentle manipulation I could feel the adhesions giving way behind like broken cheese, and within ten minutes the front part of the adhesions to the bladde mave appendix was removed, and after touching the mucous membrane with pure carbolic acid it was sutured and a patch of peritoneum fixed over it. The appendix was inflamed, and about the size of a small orange. The posterior peritoneal wound was united by chromicized catgut sutures soaked for four days in alcohol, and the same kind of sutures were used for the layers of the wound. Owing to the under surface of the caecum (which had been attached to the bladder) being denuded of peritoneum, the caecum was fixed higher up so as not to contract deep adhesions again, and a drainage tube was left in the lower end of the wound, reaching down to that part. The tube was removed in twenty-four hours.

The patient recovered with no bad symptome and a normal tempera ture, and was discharged on June $r_{3}$ th, rgo3. At the present date, July 6 th, wo pain at all, and is back at work managing a sheep station.

When long adhesions form in the abdomen, they are apt to be tense and fibrous if they are so placed as to be subject to constant movement, and they can be tied off as they have pedicles; but a sessile adhesion, although on its inner abdominal aspect it may be pretty firm, yet will be found to be quite friable if attacked from behind. Bleeding from sessile adhesions, especially when approached from behind, is rarely noticeable, or, if present, can be stopped by sponge pressure, as was done in this case. The procedure described above would, of course, not apply when suppuration is present.

\section{SUBPERITONEAL LIPOMATA.}

By JOHN CAMPBELL, M.A, M.D., F.R.C.S.ENG., Surgeon, Samaritan Hospital for Women, Belfast.

Tumours of fatty appearance which have their seat in the subperitoneal tissue are comparatively rare, but are nevertheless interesting and important from the clinical as well as from the pathological point of view. They mimic tumours of every kind krown to abdominal surgeons, and hence are liable to cause errors in diagnosis in the practice of even the most careful observers. When removed they are deceptive in appearance, so that they may belie the prognosis and cause great disappointment to both surgeon and patient. This latter tendency makes them specially interesting to the pathologist for it has of late been observed that certain tumours in this situation, which in appearance are simple lipomata, prove to be really sarcomatous in character, and after removal, recur with a fatal result.

It has been my luck to meet with two cases of subperitoneal lipoma in my operative practice, and I take this opportunity of placing them on record :

CASE I.-E. L., aged 55, single, was sent to me by Dr. J. Campbell Hall, of Monaghan, on May $18 \mathrm{th}$, I900. She complained of increase in the size of the abdomen for four years, and of emaciation for two years. She had a slight cough, and, in connexion with this, Dr. Hall called my 
attention to the rapid wasting and to pleuritic friction at the base of the left lung anteriorly. Menstruation had ceased for several years. Leucorrhoea was slight. Micturition and defaecation were attended with no difficulty, and the bowels were regular. Her nutrition was very poor. She was anaemic. There was oedema of both lungs. The heart sounds were very weak. The abdomen was greatly distended by an apparently fluctuating tumour, dull in front, but clear above and at the sides. With the view of relieving the lungs as a preliminary to operation, $I$ inserted an aspirator needle into the tumour. Needless to say no fluid was got. On May 29th Dr. M'Kinney gave her chloroform, and I opened the abdomen over the resonant area in the epigastrium, and found I had to deal with a growth in the anterior abdominal wall. It was shelled out with difficulty, owing to the vascularity of its surroundings and the multiplicity of its marginal lobules. When it had been removed it was recognized that it had occupied the subperitoneal layer, there being peritoneum alone behind it and the other structures of the abdominal wall in front of it. The tumour weighed $2 \times \frac{1}{4} \mathrm{lb}$., and filled a large toilet basin. The patient made a slow but fairly good recovery, the chief difficulty being the securing of adequate drainage of the enormous cavity. When she went home healing was not complete, there being a protrusion along the line of the wound, which was covered by sluggish granulations. About eleven months after operation I again saw her on April r 7 th, rgor. The wound was still unhealed and the abdomen was much distended by a hard dull swelling around the site of the original tumour and by a second one in the was gradually sinking, and soon afterwards she died, having lived about sixteen months after the operation.

CASE 11.-M. A. M., Ballintoy, aged 50 , married 27 years, having had eight children and one abortion, was sent to the Samaritan Hospital on August 29th, rgo2, by Dr. McIlroy, of Ballycastle. She complained of a growth in the right iliac region, which she had noticed for nine months. Menstruation had ceased eight years previously. Leucorrhoea was absent. Micturition and defaecation gave no trouble. The nutrition was good and there was no anaemia. The heart and lungs were normal The abdomen was distended on the right by an elastic rounded fixed tumour reaching to the level of the navel and dull on percussion. Per vaginam the uterus was found to be displaced to the left by a tumour in the right broad ligament. On November gth the operation was performed in Ballycastle Union Infirmary. The tumour was found to be a lipoma of the right broad ligament and iliac fossa. It was enucleated with comparative ease and the cavity drained. Under Dr. Mchroy's care she made an exce

Subperitoneal lipomata are more frequent in women than in men in the proportion of 25 to $16 .^{1}$ They occur most frequently on the right side, the neighbourhood of the kidney and the iliac fossa being their favourite sites. Clinically there are two important varieties, ${ }^{2}$ both of which are exemplified by the cases above recorded-namely, the malignant and the benign. The former include the retroperitoneal tumours, especially those which originate on the posterior aspect of the abdomen. They are difficult or impossible to remove. They are microscopically sarcomata in whole or in part. Patients afflicted with them are at first in good health, but ultimately waste markedly, while the tumour rapidly increases in size. My first case is an example of this variety. When I operated upon her I was unaware of the tendency to malignity which these seeming lipomata possess, and gave a good prognosis; consequently I was much disappointed at the result. Since then their malignant tendencies have been widely recognized, and in any future case I shall be more cautious in holding out a hope of permanent cure. The benign variety is exemplified by the second case. It includes lipomata of the broad ligament, omentum, and appendices epiploicae. These can be safely removed. They do not cause much deterioration in health and justify a good prognosis when they have been removed. The broad ligament appears to be a somewhat rare situation. ${ }^{3}$ In my case the tumour got its chief blood supply from vessels at the base of the broad ligament. It appeared to have originated there, and by its upward growth to have separated the layers of the broad ligament and extended into the iliac fossa.

1 J. G. Adami, RetroperitoneFERENCES.

1ourn Lipoma weighing $x_{3} \mathrm{lb}$. 12 oz., Journ. of Obstet. and Gyn., vol. ii, No.

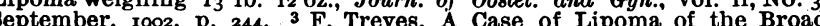
Ligament, Clin, Soc. Trans., r893, vol. xxvi, p. ror.

\section{THE TREATMENT OF VESICAL PAPILLOMA BY INJECTIONS.}

By HERBERT T. HERRING, M.B., B.S.

The difficulty of removing diffuse papilloma of the bladder and the frequency with which these simple tumours recur, even after the most severe operations, led Sir Henry Thompson and myself to seek some other means of dealing with the disease. Four years ago I published in this Journal (July 29th, 1899) the details of a new treatment by daily injections of solutions of silver nitrate and gave the results obtained in a series of cases which had been under our joint observation for a considerable number of years. Before relating other cases it may be useful perhaps to repeat briefly the method adopted.

The patient uses ( 1 ) a No. 7 soft slightly coudee catheter with the eye situated near the point, which will withstand the action of boiling water without material damage, (2) a $4 \mathrm{oz}$. indiarubber syringe fitted with a silver taper nozzle and stopcock, (3) a standard solution of nitrate of silver of $\mathrm{I} \mathrm{gr.} \mathrm{to} \mathrm{the}$ drachm of distilled water, acidulated with a small quantity of nitric acid. Before the patient can be trusted to carry out the treatment for himself $i t$ is necessary to give him a systematic course of lessons to ensure sterility during the operation, absence of injury to the organs, and the desired effect on the papilloma. The injections are commenced by adding half a grain of silver, that is, half a drachm of the standard solution to the four ounces of water contained in the syringe. The strength is gradually increased by five drops on successive duys until a drachm and a-half or two drachms are used. This very gradual addition ultimately enables the patient to use stronger solutions without pain than he could do otherwise ; for pain, straining, or frequency of micturition are indications that the treatment is too severe. The patient should only experience a slight feeling of after-warmth in the region of the bladder which should subside in the course of half an hour. The injection should be at the temperature of $100^{\circ} \mathrm{F}$., and thrown into the bladder in two parts from the syringe, each being retained a few seconds and then allowed to run out through the catheter, and as it is always advisable to rest after the application, the best time for the injection appears to be before going to bed. The treatment should be continued daily for six months or more, and then, if the conditions are favourable, it should be stopped and not resumed until blond begins to reappear, when another course of injections should be commenced.

Among the cases previously reported two have died, and the remainder, from recent reports, appear to be in good health. More than one I know considers himself entirely rid of his disease. Of the deaths one case, No. 12 in the series, died quite suddenly from cardiac failure. He had never had any return of vesical trouble from the time he first came to $m e$, weak and blanched from excessive haemorrhage, in June, 1898 , until the day of his death in May, 1900.

The second case, No. 6, died in May, 1902, aged 73. In the year previous to his death he had had frequent slight attacks of haemoptysis, much pain in the right groin and leg, which prevented his walking; he had lost weight rapidly. The prostate was hard and irregular, though the haematuria for some time had been insignificant. At the necropsy a primary malignant growth was found in the prostate, with secondary deposits in the lymphatic glands, lungs, liver, and the ascending ramus of the pubes. The surface of the mucous membrane of the bladder was rough in the region of the trigone but no papillomatous tissue was found, and the malignant growth appeared to be an independent disease. This case had been under my observation for ten years, and had been treated with the solution at regular intervals. During the early stages good specimens of papilloma were frequently found, but none recently. He was under the care of Dr. Howard Carter.

Since 1899 similar cases have come under my care, and the three following from among them go to confirm the statement that injections of nitrate of silver exercise a most important influence both in checking the haemorrhage and in retarding, if not in destroying, papillomatous growths in the bladder. They are also of special interest as giving the result of a method of treatment $f$ then suggested-namely, of employing injections after cutting operations, or when portions of the growth have been removed through the urethra by instruments.

CASE 1.-L. L., aged $5 \mathrm{r}$, was sent to me by Dr. Gesse, of Sittingbourne. He first saw blood in the urine in December, $189 x$, but had been previously treated for cystitis. In April, 1892 , haemorrhage reappeared and did so occasionally until september, 1893 , when he had an attack lasting a fortnight. Blood was seen at intervals during the following year, and in addition he complained of pain and some irritability of the bladder. In April 1894, papilloma was diagnosed. All the symptoms increased In April, 1894, papilloma was diagnosed. All the symptoms increased in severity until June, 1896 , when he was operated on by Mr. Watson Cheyne by the suprapubic method for the removal of the tumour. The patient made a rapid recovery and reture later at Christmas of the same year. It increased in frequency and severity and was accompanied by 